\title{
Impact of Cochlear Implant on Auditory and Speech Perception, and Language Development in Prelingual Deaf Children
}

\author{
MD Abu Bashar ${ }^{1 *}$ and Nazia Begam ${ }^{2}$ \\ ${ }^{1}$ Assistant Professor of Community Medicine, MM Deemed University, India \\ ${ }^{2}$ ENT specialist, ECHS Hospital, India
}

*Corresponding author: MD Abu Bashar, Assistant Professor of Community Medicine, MM Institute of medical Sciences and Research, MM Deemed University, Mullana, Haryana, India,

\section{Review Article}

Volume 5 Issue 2

Received Date: September 17, 2020

Published Date: September 30, 2020

DOI: $10.23880 /$ ooaj-16000199

Email: imback20006@yahoo.in

\section{Abstract}

Profound deafness during childhood affects the normal development of auditory and speech perception, speech production, and language skills. Cochlear implants (CIs) have revolutionized the scenario of rehabilitation of profoundly deaf individuals. A prelingual deaf is one who is congenitally deaf or whose hearing loss occurred before speech development. The current review was undertaken to assess the impact of cochlear implants (CIs) in prelingual deaf children on their hearing and speech perception, speech production and language development.

Keywords: Prelingual deafness; Cochlear implants; Speech perception; Speech production; Language development

Abbreviations: Cl's: Cochlear Implants.

\section{Introduction}

A prelingual deaf individual is one who is born with hearing loss or one whose hearing loss occurred before they began to speak [1]. It is estimated to occur in 0.5 to 3 per 1000 live births [2]. Prelingual deafness can lead to social isolation due to delayed social growth, delayed language acquisition and inability to pick up auditory social cues [3]. A cochlear implant is a small but complex electronic device that helps in hearing. It could be used by people who are deaf or hard of hearing. A cochlear implant is entirely different from a hearing aid. Hearing aids simply amplify sound, i.e. make it louder. On the other hand, cochlear implant provides useful sound information by directly stimulating the surviving auditory nerve fibres in the inner ear (cochlea) [4]. The observation that electrical stimulation of the auditory pathway can create the perception of sound was discovered in 1790 by Alessandro Volta [5].

Cochlear implants enable deaf people to receive and process sounds and speech. However, it is important to note that these devices do not restore normal hearing. Sound and speech is allowed to be processed and sent to brain by these devices [6]. Cochlear implants are usually made up of two parts. One part of the device is surgically inserted into the temporal bone surrounding the ear. It consists of a receiver-stimulator, which accepts, decodes, and then sends an electrical signal to the brain. The second part of the cochlear implant is outside the ear cavity. This is made up of a microphone/receiver, a speech processor, and an antenna. This part of the device receives the sound, converts it into an electrical signal, and sends it to the inside part of the cochlear implant which is implanted into cochlea, electrical current is then used to stimulate the remaining auditory nerve fibres [6] (Figure 1).

Both children as well as adults can be candidates for cochlear implants. They may either be born deaf or become deaf after learning to speak [7]. However, the ideal candidates with prelingual deafness are those with a regular use of hearing aid, preferably with some residual hearing, and who use oral communication [8]. Researches have shown that children with prelingual deafness can derive considerable benefit from cochlear implants [9]. 


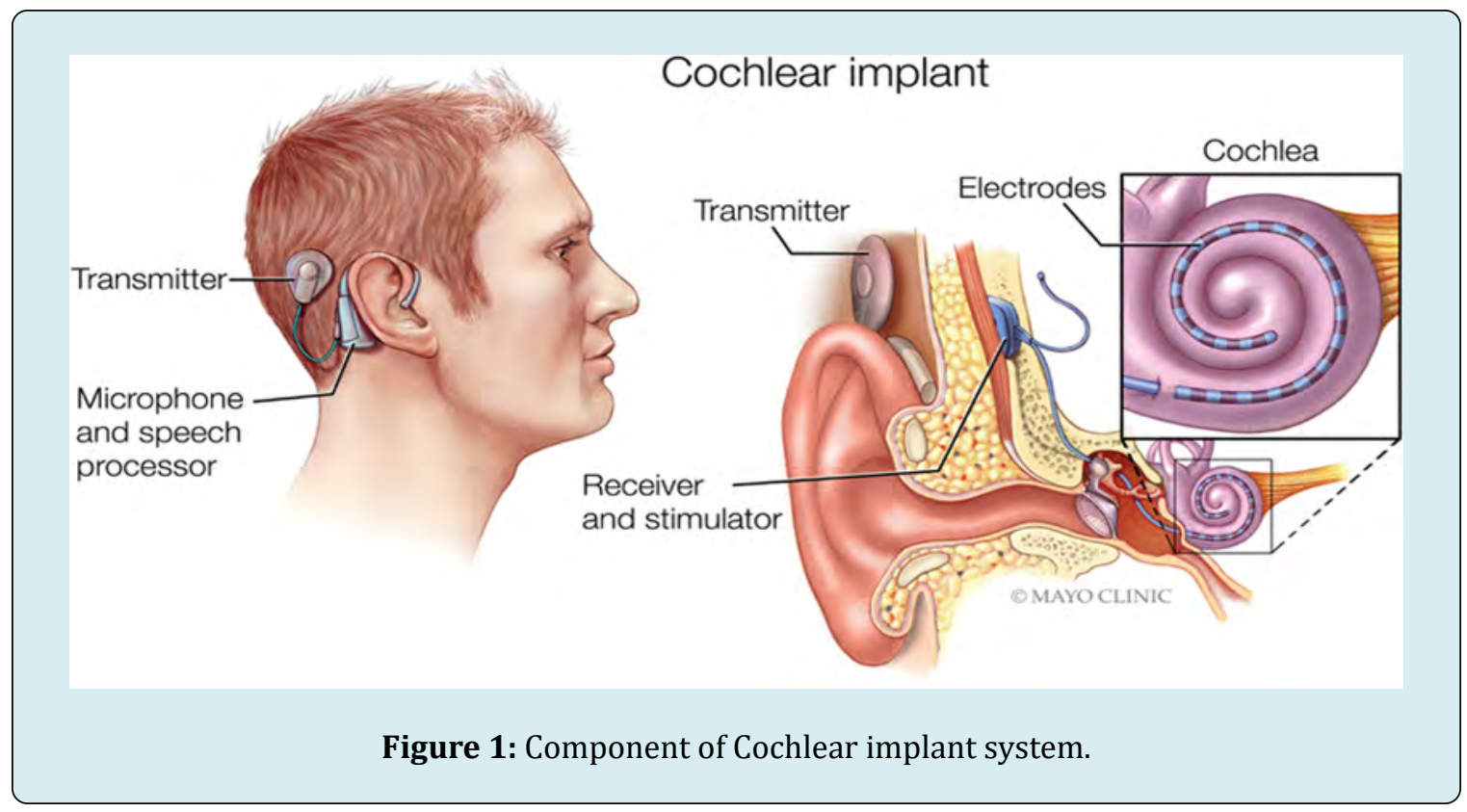

Speech is the vocalised form of human communication. It is constructed upon the syntactic combination of lexical and names that are derived from very large vocabularies. Each spoken word is designed out of the phonetic combination of a limited set of vowels and consonant sound units. Speech perception refers to the processes by which humans are able to interpret and comprehend the sounds used in different languages [10].

Language development is the process by which children learn to understand and communicate language during childhood. From birth up to five years of age, children develop language at a very rapid pace. It may be noted that the stages of language development are common in all humans. However, the age and the speed at which a child reaches each milestone of language development greatly vary. Thus, language development in an individual child must be compared with norms rather than with other individual children. More than any other feature of development, language development reflects the growth and maturation of the brain. Receptive language development (the ability to comprehend language) usually develops faster than expressive language (the ability to communicate) [11].

Hearing or audition is the ability to perceive sound by sensing vibrations through an organ such as ear. The inner ear is fully developed by the time the mother is approximately 20 weeks pregnant and new-borns have fully developed hearing mechanism [12]. The present review is undertaken to assess the impact of cochlear implant surgery on auditory perception, speech and language development in prelingual deaf children.

\section{Studies on Impact of Cochlear Implants (CIs) on Auditory and Speech perception, Speech Production and Language development}

\section{Impact on Auditory Perception}

A number of studies have shown significant increase in auditory perception abilities after cochlear implantation in profoundly deaf children [13-15]. Furthermore, CIs proved to provide deaf children with auditory access to spoken language, reflected in increasing receptive vocabulary [1619].

Govaerts, et al. [20] evaluated data from six age cohorts implanted up to 6 years of age. They assessed the auditory performance (using the Categories of Auditory Performance questionnaire) preoperatively and up to 2 years after cochlear implantation. The CAP scores were rapidly (within 3 months) normalised in children implanted before the age of 2 years. Children implanted later, took longer to achieve scores similar to their normal-hearing peers. Around 25\% of children implanted after their third birthday could not achieve normal CAP scores within the first 48 months after implantation. Furthermore, this outcome was rarely achieved in children implanted after the age of 4 years.

Schauwers, et al. [21], investigated the audiological outcome of 10 deaf children and found that the earlier the implantation took place, the smaller the delay was in comparison with normally hearing children with regard to auditory performance as measured by CAP. Those children implanted in first year of their life exhibited a normal CAP development as soon as 3 months after implantation. 


\section{Otolaryngology Open Access Journal}

\section{Impact on Speech Perception \& Production}

Speech perception includes both the perception of a stimulus and its interpretation, the process being described through various models and theories. According to the auditory theory of speech perception, ordinary auditory processes are sufficient to explain the perception of speech [22]. The auditory appearances of acoustic patterns are registered and matched with phonetic, categorical labels that already persist in the memory. The motor theory of speech perception is based on the hypothesis that the intended phonetic gestures of the speaker construct the basis for phonetic categories [23].

Hasenstab \& Tobey in their study found the evidence of doubling of speech intelligibility after one year use of cochlear implant [24]. Pisonni, et al. [25] concluded that children with cochlear implants show better speech and language outcomes after implantation, and their performances continue to increase over time. Tomblin, et al. [26] also found significant improvement in speech after cochlear implantation.

O'Donoghou, et al. [27] examined 40 children with mean age at implantation of 52 months who were prelingually deaf and were followed up for 5 years. The mean 52 number of words per minute perceived increased from 0 before implantation to $44^{\circ} 8$ (SD 24.3), 5 years after implantation. Repeated-measures ANOVAshowed thatchildren significantly improved over time $\left(\mathrm{p}=0^{*} 001\right)$. Age at implantation was a significant covariate $\left(\mathrm{p}=0{ }^{\circ} 01\right)$ and mode of communication was a significant between-individuals factor $\left(p=00^{* 04}\right)$. Early age at intervention and oral communication mode were the most vital determinants of later speech perception in young children after cochlear implantation.

Holt, et al. [28] in a prospective study compared speech perception of congenitally deaf children who received cochlear implants before the age of 5 years. Five of these children received their implants between 7-12 months of age, 27 between 13-24 months of age, 38 between $25-36$ months of age and 23 between 37-48 months of age. Speech recognition was better for children implanted early in their life than those implanted later. This was shown by better performance in children implanted in their second year of life (average word recognition score $=70 \%$ ) than those implanted in their third (52\% score) and fourth (33\%) years of life.

In an another study by Manrique, et al. [29], Speech perception ability was tested and shown to be correlated with age at implantation in their prospective cohort study. The study was performed to evaluate and compare outcomes of 94 children with bilateral profound hearing impairment who were consecutively implanted with cochlear implants before their second birthday to 36 children implanted between 2-6 years of age. Children were then followed up for 5-8 years. They concluded that infants implanted before the age of 2 years showed better auditory perception and speech perception test results than those implanted at a later age. Children implanted before the age of 2 followed a relatively normal development of language, whereas older children showed a lag of approximately 2 years when compared with the normal baseline.

\section{Impact on Language Development}

Deaf children show a significant delay in both vocabulary and grammar when compared to same-age hearing children. Normally, a three-year-old is expected be to produce 9001,000 different words and to use those words to produce sentences that are about 3-4 words in length and include a subject and a verb [30]. In comparison, profoundly deaf children have demonstrated a much lower level of vocabulary and grammar skills [31].

Lederberg and Spencer highlighted that deaf children lack a "spurt" in vocabulary development, which is characteristic in normal hearing children" [32]. In their longitudinal study, Kirk, et al. [33] studied the rate of growth in word recognition and language skills as a function of age at cochlear implantation and whether there are any sensitive periods for cochlear implantation before the age of 3 years. They prospectively followed up 106 pre-lingual deaf children who received their cochlear implants at either $<2$ years, between 2-4 years, or at age 5 or older. A battery of speech and language outcome measures were administered to the children before the implantation and six monthly after the implantation for minimum 3 years. Data from two measures of spoken word recognition and from two measures of receptive and expressive language were analysed with the length of device use, age at implantation, and communication mode as the co-variates. The study showed significant improvements in spoken word recognition and receptive and expressive language skills following cochlear implantation. It was found that the age equivalent vocabulary scores of children who received cochlear implants when they were 5 years old were 0.72 to 0.80 relative to their CA (chronological age) (i.e., age-equivalent score/CA) after 2 years of cochlear implantation.

Szagun G prospectively followed-up twenty-two young German-speaking deaf children implanted with cochlear implants (mean age at implantation 29 months). Language acquisition in terms of progress in grammar and vocabulary of these children was compared to that of a group of 22 normal-hearing children over a period of 27 to 36 months. The study found that patients show improvement after cochlear implant [34]. 


\section{Otolaryngology Open Access Journal}

Hammes, et al. [35] retrospectively analysed data on 12 infants with hearing loss who received cochlear implants before the age of 18 months. These were compared to 13 infants who received their implants between 19-30 months of age, 11 children implanted between 31-40 months, and to 11 children who received their implants between 4148 months. Comparisons based on age at implantation were performed using spoken language measures. Spoken language data were reviewed for the children who underwent at least 6 months of cochlear implant use to assess the rate of progress and performance for the group of children who received their cochlear implants between 9 and 18 months of age. The study indicated that children fitted with cochlear implants at an early age showed improvement in expressive and receptive language capabilities as well as developed speech and language skills at the same rate as normal hearing children. Furthermore, children who had their implants inserted at or before the age of 18 months showed the best outcome. Analyses revealed that $70 \%$ of those implanted by 18 months, $30 \%$ of those implanted between $19-30$ months, $<10 \%$ of those implanted between $31-40$ months, and $<5 \%$ of those implanted between 41-48 months had a spoken language age within 1 year of their chronologic age.

Fukuda, et al. [36] reported a case study of a 10-yearold congenitally deaf child who received a cochlear implant at the age of 4 years. Before implantation, his language development was delayed by 34 months in comparison with his chronological age. This gap was narrowed to a 23-month delay, 2 years after surgery. The child was also able to use intelligible three-word sentences within 2 years of implantation.

Svirsky, et al. [15] in their study compared the speech perception and language skills of congenitally deaf children who received cochlear implants in the second year of life (12 children), third year of life (34 children) or fourth year of life (29 children). Analyses showed close language scores for cochlear implant users to average values from normal-hearing children as a function of age. The average projected language age for children implanted between 12 and 24 months (measured in units of language age) was 5.7 months higher than for children implanted at 25-36 months at the same chronological age. Children implanted after 3 years of age lagged behind those implanted between 2536 months by 5.6 months $(\mathrm{p}<0.05)$, and those implanted at $12-24$ months by 10 months $(\mathrm{p}<0.001)$. Similarly, speech perception capacity was correlated with age at implantation, and children who received cochlear implants before their second or third birthday showed better rates of perception than those implanted after their third birthday.

Manrique, et al. [29] measured the spoken language of 36 children with cochlear implants by using the General Oral
Expression scale of the Reynell Developmental Language Scales III. It was found that those receiving an implant by age two years had a normal rate of growth though one year delayed whereas children receiving an implant between two and six years exhibited a slower growth rate and a lag of two to three years below achievement levels for hearing agemates.

Nicholas and Geers examined data from 76 profoundly deaf children attending oral education programmes or therapy practices, who received a cochlear implant between the ages of 12 and 38 months [16]. They concluded that the amount of spoken language exhibited by profoundly deaf 3-year-old children was mostly related to the length of time of cochlear implant use in infancy and very early childhood. The study also found a lessening in the gap between a deaf child's chronological age and the child's spoken language level with younger age at cochlear implantation [16].

\section{Conclusion}

The cochlear implants are a highly effective treatment for rehabilitation of prelingual deaf children, although complex due to the interaction of variables which affect the implanted child's performance. The factors influencing the impact of CIs on auditory and speech perception and language development among these children are: child's age at the time of implantation, time of hearing sensorial deprivation, duration of use of cochlear implant and type of and speech codification strategy used. However, further longitudinal studies are needed to better understand the implantation complexity and its impact in prelingual deaf children.

\section{References}

1. Gleason JB, Ratner NB (2009) The development of language $7^{\text {th }}(E d n$.$) , Boston: Pearson.$

2. Chaturvedi A, Mohan C, Mahajan SB, Kakkar V (2006) Imaging of Cochlear Implants. Ind J Radiol Imag 16(3): 385-392.

3. (2004) Hearing Loss: Determining Eligibility for Social Security Benefits. In: Dobie RA, et al. (Eds.), Washington (DC): National Academies Press (US), 7, Hearing Loss in Children.

4. Cochlear Implants. National Institute of Deafness and Other Communication Disorders.

5. Eshraghi AA, Nazarian R, Telischi FF, Rajguru SM, Truy E, et al. (2012) The cochlear implant: historical aspects and future prospects. Anat Rec (Hoboken) 295(11): 19671980. 


\section{Otolaryngology Open Access Journal}

6. Wilson BS (2000) Cochlear Implant Technology; Cochlear Implants: Principles and Practices, pp: 109-127.

7. Deep NL, Dowling EM, Jethanamest D, Carlson ML (2019) Cochlear Implantation: An Overview. J Neurol Surg B Skull Base 80(2): 169-177.

8. Nikolopoulos TP, O Donoghue GM, Archbold S (1999) Age at Implantation: Its Importance in Paediatric Cochlear Implantation; Laryngoscope 109(4): 595-599.

9. Teoh SW, Pisoni DB, Miyamoto RT (2004) Cochlear implantation in adults with prelingual deafness. Part I. Clinical results. Laryngoscope 114(9): 1536-1540.

10. Masur EF (1995) Infant's early verbal imitation and their later lexical development. Merrill-Palmer Quarterly 41(3): 286-306.

11. Bochner AP, Ellis C (2003) An Introduction to the Arts and Narrative Research: Art as Inquiry. Qualitative Inquiry 9(4): 506-514.

12. Korver AM, Smith RJ, Van Camp G, Schleiss MR, Glindzicz MAKB, et al. (2017) Congenital hearing loss. Nat Rev Dis Primers 3: 16094.

13. Meyer TA, Svirsky MA, Kirk KI, Miyamoto R (1998) Improvements in speech perception by children with profound prelingual hearing loss: Effects of device, communication mode, and chronological age. J Speech Lang Hear Res 41(4): 846-858.

14. Robbins AM, Koch DB, OsbergerMJ, Zimmerman Phillips S, Kishon Rabin L (2004) Effect of Age at Cochlear Implantation on Auditory Skill Development in Infants and Toddlers. Arch Otolaryngol Head Neck Surg 130(5): 570-574.

15. Svirsky MA, Teoh SW, Neuburger H (2004) Development of language and speech perception in congenitally, profoundly deaf children as a function of age at cochlear implantation. Audiol Neurootol 9(4): 224-233.

16. Geers A, Nicholas J, Sedey A (2003) Language Skills of Children with Early Cochlear Implantation. Ear Hear 24(1): 46-58.

17. Miyamoto R, Houston DM, Kirk KI, Perdew AE, Svirsky MA (2003) Language development in deaf infants following cochlear implantation. Acta Otolaryngol 123(2): 241-244.

18. Svirsky MA, Robbins AM, Kirk KI, Pisoni DB, Miyamoto RT (2000) Language development in profoundly deaf children with cochlear implants. Psychol Sci 11(2): 153158.
19. Vermeulen A, Hoekstra C, Brokx J, van den Broek P (1999) Oral language acquisition in children assessed with the Reynell Developmental Language Scales. Int J Pediatr Otorhinolaryngol 47(2): 153-155.

20. Govaerts PJ, De Beukelaer C, Daemers K, De Ceulaer G, Yperman M, et al. (2002) Outcome of Cochlear Implantation at Different Ages from 0 to 6 Years. Otol Neurotol 23(6): 885-890.

21. Schauwers K, Gillis S, Daemers K, De Beukelaer C, Govaerts PJ (2004) Cochlear Implantation Between 5 and 20 months of Age: the Onset of Babbling and the Audiologic Outcome. Otol Neurotol 25(3): 263-270.

22. Lindblom B (1990) Explaining Phonetic Variation: A Sketch of the H\&H Theory. In: Hardcastle WJ, (Eds.), Speech Production and Speech Modelling. NATO ASI Series. Springer, Dordrecht, 55: 403-439.

23. Liberman AM, Mattingly IG (1985) The motor theory of speech perception revised. Cognition 21(1): 1-36.

24. Tobey E, Hasenstab M (1991) Effects of a Nucleus Multichannel Cochlear Implant upon Speech Production in Children. Ear Hear 12(4): 48-54.

25. Pisoni DB, Cleary M, Geers AE, Tobey EA (1999) Individual Differences in Effectiveness of Cochlear Implants in Children Who Are Prelingually Deaf: New Process Measures of Performance. Volta Rev 101(3): 111-164.

26. Tomblin JB, Spencer L, Flock S, Tyler R, Gantz B (1999) A comparison of language achievement in children with cochlear implants and children using hearing aids. J Speech Lang Hear Res 42(2): 497-511.

27. O Donoghue GM, Nikplopoulos TP, Archbold SM (2000) Determinants of speech perception in children after cochlear implantation. Lancet 356(9228): 466-468.

28. Holt RF, Svirsky MA, Neuburger H, Miyamoto RT (2004) Age at implantation and communicative outcome in pediatric cochlear implant users: Is younger always better? International Congress Series 1273: 368-371.

29. Manrique M, Cervera Paz FJ, Huarte A, Molina M (2004) Advantages of Cochlear Implantation in Prelingual Deaf Children Before 2 Years of Age when Compared with Later Implantation. Laryngoscope 114(8): 1462-1469.

30. Owens RE (2005) Language development: An introduction. $6^{\text {th }}$ (Edn.), Allyn \& Bacon Publishers, Boston.

31. Nicholas JG (2000) Age differences in the use of 


\section{Otolaryngology Open Access Journal}

informative/heuristic communicative functions in young children with and without hearing loss who are learning spoken language. Journal of Speech, Language, and Hearing Research 43(2): 380-394.

32. Lederberg, AR, Spencer, PE (2001) Vocabulary development of deaf and hard of hearing children. In: Clark MD, et al. (Eds.), Context, cognition and deafness, Washington, DC: Gallaudet University Press, pp: 88-112.

33. Kirk KI, Miyamoto RT, Lento CL, Ying E, Neill TO, et al. (2002) Effects of age at implantation in young children. Ann Otol Rhinol Laryngol 189: 69-73.
34. Szagun G (2001) Learning different regularities: the acquisition of noun plurals by German-speaking children. First Language 21(62): 109:141.

35. Hammes DM, Novak MA, Rotz LA, Willis M, Edmondson DM, et al. (2002) Early identification and cochlear implantation: critical factors for spoken language development. Ann Otol Rhinol Laryngol Suppl 189: 7478.

36. Fukuda S, Fukushima K, Maeda Y, Tsukamura K, Nagayasu R, et al. (2003) Language development of a multiply handicapped child after cochlear implantation. Int J Pediatr Otorhinolaryngol 67(6): 627-633. 